\title{
THE PALEONTOLOGICAL RECORD FROM SOUTHERN FLORIDA: APPLICATION TO RESTORATION OF THE EVERGLADES ECOSYSTEM
}

WILLARD, Debra A., U.S. Geological Survey, 926A National Center, Reston, VA 22092, U.S.A.; BREWSTER-WINGARD, G. Lynn, U.S. Geological Survey, 926A National Center, Reston, VA 22092 U.S.A.; HOLMES, Charles W., U.S. Geological Survey, MS 972, Denver Federal Center, Denver, CO 80225, U.S.A.

Efforts to restore threatened ecosystems often aim to return the ecosystem to some "original" state, typically defined as the pristine condition that existed prior to the onset of substantial human activity in the area. Historical data, such as aerial photographs or anecdotal evidence that cover time periods on the order of the last century frequently are used to define this state. To accurately interpret the natural range of variability within an ecosystem, however, it is necessary to consider longer time scales, ranging at least from centuries to millennia. Paleontological data provide the ideal means to reconstruct biotic communities over extended time periods, particularly when integrated with chronological and geochemical data. In addition, fossil data provide clues to the physical and chemical parameters that existed within the ecosystem at any given point in time and the response of communities to changes in environmental parameters.

Southern Florida is an ideal region to showcase the applicability of paleontological and paleoecological analyses to ecosystem restoration efforts. Over the last century, the hydrologic regime of southern Florida has been profoundly altered through construction of an extensive levee and canal system that has drained nearly half of the historical Everglades for development and agriculture.

Vegetational changes and a decline in wading bird populations in the Everglades have been attributed to alteration of water levels and hydroperiods and intermittent water flow through the system. Alteration of the terrestrial regime also is thought to be responsible for changes in salinity levels in Florida Bay, which in turn caused declines in sea grass beds and fish and invertebrate populations. However, the impact of natural environmental changes, such as sea-level rise and climate, has not been documented for this ecosystem. Currently, efforts are underway to restore the southern Florida ecosystem to as natural a state as possible.

Paleontological data are being used to 1) determine changes in floral and faunal composition of the region over the last 150 years; 2) establish the baseline level of floral and faunal variation; and 3) correlate biotic changes with known changes in environmental forcing factors, whether natural or anthropogenic. Cores from sites throughout southern Florida and Florida Bay are being analyzed for pollen, mollusks, ostracodes, foraminifers, and dinocysts; ${ }^{210} \mathrm{~Pb}$ and ${ }^{226} \mathrm{Ra}$ analyses provide critical age control over the last 150 years, and ${ }^{14} \mathrm{C}$ analyses provide ages for older parts of the cores. Modern assemblages from across the region are being quantified to provide data for determination of closest modern analogs for fossil assemblages. Changes in floral and faunal abundance are recorded over the last 150 years in these cores, and several changes appear to be approximately synchronous across the ecosystem. Around 1960, Florida Bay sediments record decreases in submerged aquatic vegetation and decreases in benthic faunal abundance and diversity. Pollen assemblages indicate a contemporaneous decrease in sawgrass abundance in near-shore peats and an increased abundance of mangroves and hardwoods. Farther inland, at a cattail-affected site in the water conservation areas, a change to vegetation with a greater abundance of cattails also is recorded at about 1960 . This corresponds to changes in the geochemical record, including increases in phosphorous, nitrogen, and other elements. Natural environmental changes, such as hurricanes or sea-level rise, and anthropogenic changes can be correlated to the pattern of biotic change detected in cores from throughout the region. Careful comparison of the timing of the environmental and biotic changes enables determination of cause-and-effect relationships; such an ability is crucial for prediction of future biotic response to planned changes in the hydrologic regime of southern Florida. The floral and faunal records from these cores also provide the baseline level of biotic variability for this ecosystem, which is required by resource managers for their definition of the pristine Everglades ecosystem. 